\title{
SHEETFLOW SEDIMENT TRANSPORT UNDER ASYMMETRIC WAVES AND STRONG CURRENTS
}

\author{
Le Phuong Dong ${ }^{1}$ and Shinji Sato ${ }^{1}$
}

\begin{abstract}
Experiments have been conducted to investigate the sheetflow sediment transport of uniform sand under asymmetric oscillatory flows in combination with relatively strong opposite currents. Two kinds of nearshore waves were performed, namely, velocity asymmetric waves and acceleration asymmetric waves. Image analysis technique is utilized to study major influences of wave shapes and current through observing the instantaneous sheetflow layer thickness. Maximum sheetflow layer thickness was formulated and incorporated to an enhanced Watanabe and Sato's formulation. The new conceptual model is examined its validity for a wide range of experimental conditions
\end{abstract}

Keywords: sheetflow; oscillatory flow; sediment transport; net transport rates formula; asymmetric waves; currents

\section{INTRODUCTION}

Interaction of nearshore waves and strong currents is often observed at the river mouths where mean current velocity of outflow $u_{c}$ is often comparable to the maximum near bottom orbital velocity $u_{w}$. For instance, at Ba Lat river mouth, the largest tributary of Red River Basin, Vietnam, measured data show that the ratio between $u_{c} / u_{w}$ is often larger than 0.5 (Pruszak et al. 2005). This phenomenon thus effects to the sediment transport and topography changes in these areas. Under such conditions, sheetflow transport regime is predominant as the Shields parameter is often large enough to wash out sand ripples and transport sediment in a thin layer of a few $\mathrm{mm}$ to $\mathrm{cm}$ with high sand concentration along the bed. Since observing and measuring the sheetflow sediment transport in the field is somehow difficult because it occurs very much closed to the sea bottom, indoor oscillatory flow tunnel measurement is an effective and economical approach to study various physical aspects of sheetflow sand movement. Due to the limitation of experimental facilities, few studies have been conducted with waves superimposed currents. Dohmen-Janssen (1999) is among the first study that measured the sediment transport under sinusoidal waves combined with relatively strong currents (Fig.1). However, in the surf zone (river mouth regions), asymmetric waves are dominant. Both field measurement (Elgar and Guza 1985) and wave flume data (Sato et al. 1992) show that velocity asymmetric waves with sharp crest and flat trough (Fig 2a) are developed just around the breaker line, whereas the acceleration asymmetric waves with saw-tooth shapes are formed near the shore. As a consequence, the existence of different wave shapes may lead to different sediment transport behaviors. Up to now, various papers have been published on such topic, however, there have been a small number of studies investigating about sediment transport under such kind of waves and steady currents with relatively small velocity against waves. Dibajnia and Watanabe (1992) carried out a series of oscillatory experiments with and without steady current to study the effect of wave nonlinearity in sediment transport. However, the superimposed current is restricted as the current to wave amplitude ratio is smaller than 0.3 (Fig.2). In the experiments performed with acceleration asymmetric oscillation, Watanabe and Sato (2004) added opposite steady currents to illustrate the effects of undertow but the ratio $u_{c} / u_{w}$ is also smaller than 0.3 (Fig 2). Still the existing researches on net transport rate models under collinear asymmetric wavesstrong currents produce the undecided conclusion due to the lack of concrete evidences. This study attempts to deliver new experiments performed with different asymmetric oscillatory flow conditions in combination with relatively strong superimposed current generated in the opposite direction with waves (focus of this study is highlighted by red solid symbols, Fig.1). It aims to further examine the role of strong opposite current on the net transport rates under oscillatory flow conditions. On the basis of image analysis technique, instantaneous sheetflow layer thickness was measured and its maximum values are formulated. Incorporating the new expression for maximum sheetflow layer thickness, a new model based on Watanabe and Sato (2004)'s conception has been proposed and its applicability for a wide range of experimental conditions is verified.

\footnotetext{
${ }^{1}$ Department of Civil Engineering, The University of Tokyo, 7-3-1 Hongo, Bunkyo-ku, Tokyo, 113-8656, Japan;
} 


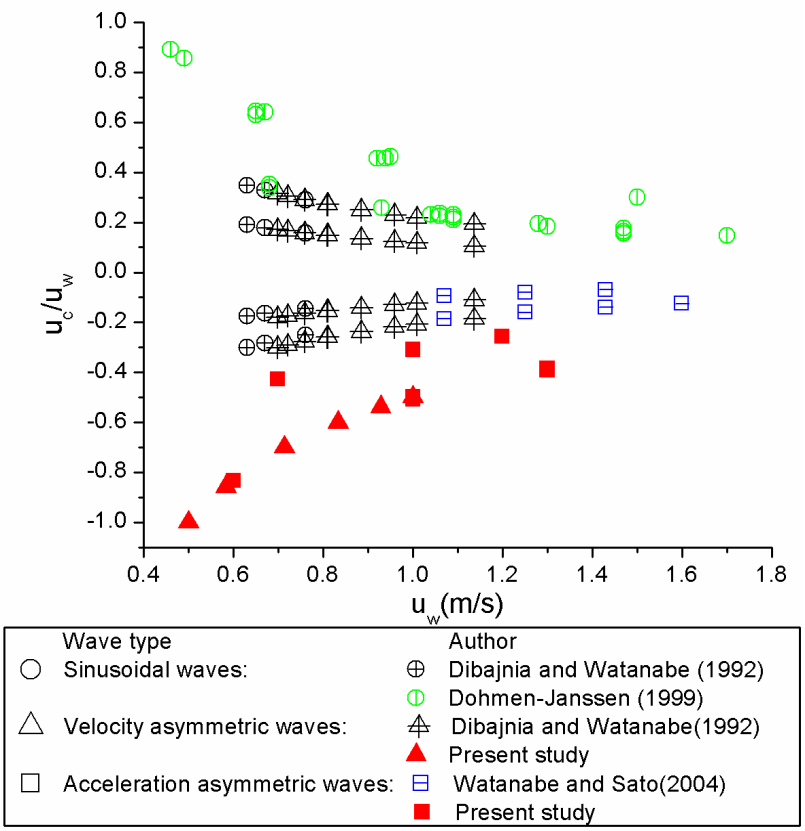

Figure 1. Existing studies and present experiments on sheetflow sediment transport under waves and currents (positive sign means currents were generated in the same direction with waves and vice versa).
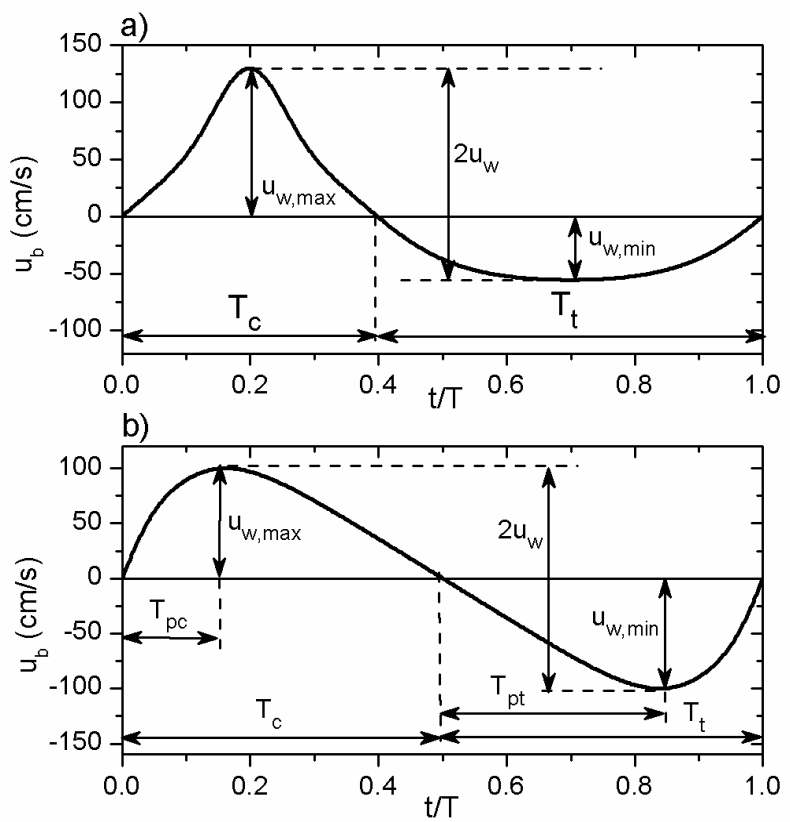

Figure 2. A typical bottom velocity profile of : a) Velocity asymmetric waves. b) Acceleration asymmetric waves

\section{EXPERIMENTS}

A set of experimental data has been obtained using the Oscillatory Flow Tunnel (OFT) at the University of Tokyo. The OFT consists of a loop-shaped closed conduit and a hydraulically driven piston. Negative or positive current to oscillatory flow can be generated through a circulation system that controlled by a hydraulic pump. The rectangular horizontal tunnel test section is $5.7 \mathrm{~m}$ in length, height of $23.3 \mathrm{~cm}$ and width of $7.6 \mathrm{~cm}$. The central $4.3 \mathrm{~m}$ of the test section with mild slopes at both ends is filled with $4.0 \mathrm{~cm}$ deep uniform sand $\left(d_{50}=0.2 \mathrm{~mm}\right)$. Asymmetric oscillations with the period $T=3 \mathrm{~s}$ and the wave amplitude $u_{w}$ varied from 0.6 to $1.3 \mathrm{~m} / \mathrm{s}$ (Fig.1) have been generated with different 
wave shapes based on the third order cnoidal wave theory. The waves shape is characterized by the asymmetric velocity index $R_{v}$ :

$$
R_{v}=\frac{u_{\max }}{u_{\max }-u_{\min }}
$$

and the dimensionless acceleration asymmetry index $\beta_{i}$ :

$$
\beta_{i}=1-\frac{T_{p i}}{T_{i}}
$$

where $u$ is the flow velocity; subscript ( $i=c$ or $t$ ) denotes for crest or trough with $T_{i}$ being the half wave period (s); $T_{p i}$ is the time from the flow reversal to the maximum velocity at each half cycle (Fig.2). Noted that the definition of $\beta_{i}$ in Eq.(2) satisfies $\beta_{c}+\beta_{t}=1$. In total, two kinds of both velocity asymmetry waves with $R_{v}=0.6$ and 0.8 and acceleration asymmetry waves with $\beta_{c}=0.55$ and 0.68 were performed. Relatively strong superimposed currents are generated in opposite direction with waves at velocity of 0.3 and $0.5 \mathrm{~m} / \mathrm{s}$ which results in the current to wave amplitude ratio between -1 and -0.3 as shown in figure 1 . Table 1 listed experimental setup performed in this study. In total, 18 experiments were performed and no bed forms were generated for all cases that assure the sheetflow regime. Experimental processes were recorded with a high speed video camera (400 frames/s). Net transport rates were measured for 17 cases, while case 18 were performed to examine the calibration relationship between brightness and sand concentration. The net transport rates were estimated on the basis of sand mass difference in two halves of the tunnel after an experimental duration $\Delta t$ as follows (Dibajnia et al. 2001):

$$
q_{\text {meas }}=\frac{\Delta M_{\text {on }}-\Delta M_{o f f}}{2 b \rho_{s} \Delta t}
$$

where $q_{\text {meas }}$ is measured net sediment transport; $\Delta M_{o n}, \Delta M_{\text {off }}$ is the difference in the sand mass on the onshore and offshore side before and after experiment, respectively; $b$ is the width of test section; $\rho_{\mathrm{s}}=$ $2.65 \mathrm{~g} / \mathrm{cm}^{3}$ is the sediment density.

\begin{tabular}{|l|l|l|l|l|l|l|l|l|}
\hline \multicolumn{7}{|c|}{ Table 1. Experimental conditions in the present study. } \\
\hline Case & $\begin{array}{l}d_{50} \\
(\mathrm{~mm})\end{array}$ & $\begin{array}{l}T \\
(\mathrm{~s})\end{array}$ & $\begin{array}{c}u_{w} \\
(\mathrm{~m} / \mathrm{s})\end{array}$ & $R_{v}$ & $\boldsymbol{\beta}_{c}$ & $\begin{array}{l}u_{c} \\
(\mathrm{~m} / \mathrm{s})\end{array}$ & $\Delta t(\mathrm{~s})$ & $\begin{array}{l}q_{\text {meas }} \\
\left(\mathrm{cm}^{2} / \mathrm{s}\right)\end{array}$ \\
\hline 01 & 0.2 & 3.0 & 1.00 & 0.5 & 0.55 & -0.31 & 45.00 & -0.566 \\
02 & 0.2 & 3.0 & 1.20 & 0.5 & 0.55 & -0.31 & 34.50 & -0.480 \\
03 & 0.2 & 3.0 & 0.70 & 0.5 & 0.55 & -0.30 & 37.54 & -0.232 \\
04 & 0.2 & 3.0 & 1.00 & 0.5 & 0.55 & -0.50 & 34.50 & -1.664 \\
05 & 0.2 & 3.0 & 0.60 & 0.5 & 0.55 & -0.50 & 34.75 & -0.818 \\
06 & 0.2 & 3.0 & 1.30 & 0.5 & 0.55 & -0.50 & 30.80 & -1.814 \\
07 & 0.2 & 3.0 & 1.00 & 0.5 & 0.68 & -0.51 & 36.83 & -0.687 \\
08 & 0.2 & 3.0 & 1.30 & 0.5 & 0.68 & -0.52 & 39.17 & -0.231 \\
09 & 0.2 & 3.0 & 0.60 & 0.5 & 0.68 & -0.50 & 35.08 & -0.647 \\
10 & 0.2 & 3.0 & 1.30 & 0.5 & 0.68 & -0.50 & 34.56 & -0.177 \\
11 & 0.2 & 3.0 & 0.60 & 0.5 & 0.68 & -0.50 & 31.15 & -0.844 \\
12 & 0.2 & 3.0 & 0.58 & 0.6 & 0.5 & -0.50 & 31.12 & -0.833 \\
13 & 0.2 & 3.0 & 0.83 & 0.6 & 0.5 & -0.50 & 32.10 & -1.562 \\
14 & 0.2 & 3.0 & 1.00 & 0.6 & 0.5 & -0.50 & 31.31 & -1.445 \\
15 & 0.2 & 3.0 & 0.50 & 0.7 & 0.5 & -0.50 & 33.18 & -0.431 \\
16 & 0.2 & 3.0 & 0.71 & 0.7 & 0.5 & -0.50 & 34.30 & -0.446 \\
17 & 0.2 & 3.0 & 0.93 & 0.7 & 0.5 & -0.50 & 34.31 & -0.986 \\
18 & 0.2 & 3.6 & 1.27 & 0.5 & 0.5 & 0.00 & - & - \\
\hline
\end{tabular}

In order to study the sand motions processes, image analysis technique was utilized. The back side wall of test section was painted in black, so sand particle is the only source of light reflection. A larger brightness value may correspond to a higher sand concentration and vice versa. It is expected that the changes of sand concentration may change the spatial distribution of brightness. At the unmovable bed, the brightness reaches the maximum value where the maximum sand concentration is located. In order to establish a relationship between sand concentration and brightness, the illumination conditions were kept stable for all experiments. It can be achieved by adjusting beforehand the angles of spot lights and 
the aperture of camera's curtain. Figure 3 illustrates the relationship between time average brightness and the sand concentration for experimental case 18. This experiment was performed under the same condition with case 1-1 in Horikawa et.al (1982) in which sand concentration was spatially measured. In the present study, sheetflow layer thickness is of interest since it is experimentally observed that 8090\% of sand is transported in this layer (Dohmen-Janssen et al. 2001). Many researchers (e.g, DohmenJanssen et al. 2001, O'Donoghue and Wright 2004a) defined such thickness as the distance between undisturbed beds to the elevation where sand concentration equals to $8 \mathrm{vol} \%$ (approximate $200 \mathrm{~g} / \mathrm{l}$ ). The temporal sheetflow layer thickness in present study is estimated in analogy with previous researches but was correlated with brightness value. Since the sheetflow layer thickness can be measured through a certain ratio between suspended sand concentration and the maximum sand concentration at stationary bed, it is also expected that the thickness of sheet layer can also be measured by considering the relative relationship of temporal distribution of brightness above the bottom with the maximum value at unmovable bed. From figure 3, it is found that at the elevation where sand concentration equal to 200 $\mathrm{g} / \mathrm{l}$ the brightness value reduces to 95 . This brightness value corresponds to approximate $55 \%$ of maximum brightness value $\left(b_{\max }=175\right)$. Sheetflow layer thickness is measured here as the distance between undisturbed bed where brightness is relatively maximum and the level where brightness relatively reduces to $55 \%$ maximum brightness value.

However, it may be argued that it is somehow difficult to keep the experimental conditions stable for all the tests. In order to further examine this, experimental condition 18 was repeated 3 times but the brightness was varied by changing the aperture of camera in each test. Figure 4 shows the smoothed out temporal sheetflow layer thickness for experimental case 18 under different illumination conditions $\left(b_{\max }\right)$. As can be seen from the figure, even for large different between maximum brightness values, measurement of maximum sheetflow layer thickness are acceptable as the errors are as small as $1 \mathrm{~mm}$. Therefore, it is concluded that a small fluctuation of illumination condition may not affect so much to the experimental results.

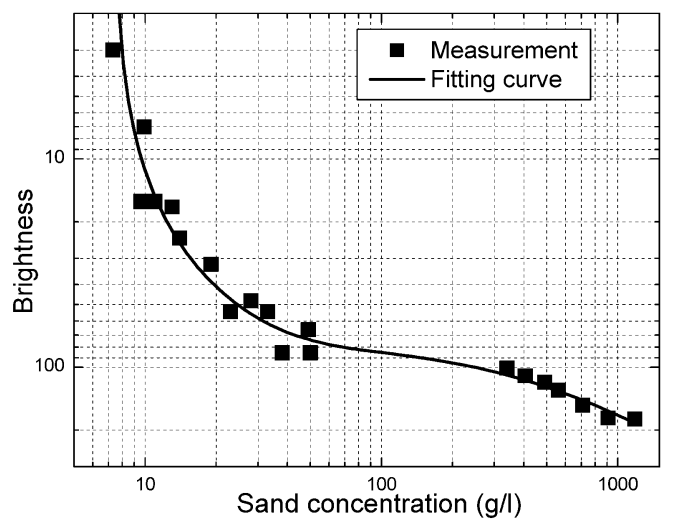

Figure 3. Relationship between measured time average sand concentration and brightness for case 18

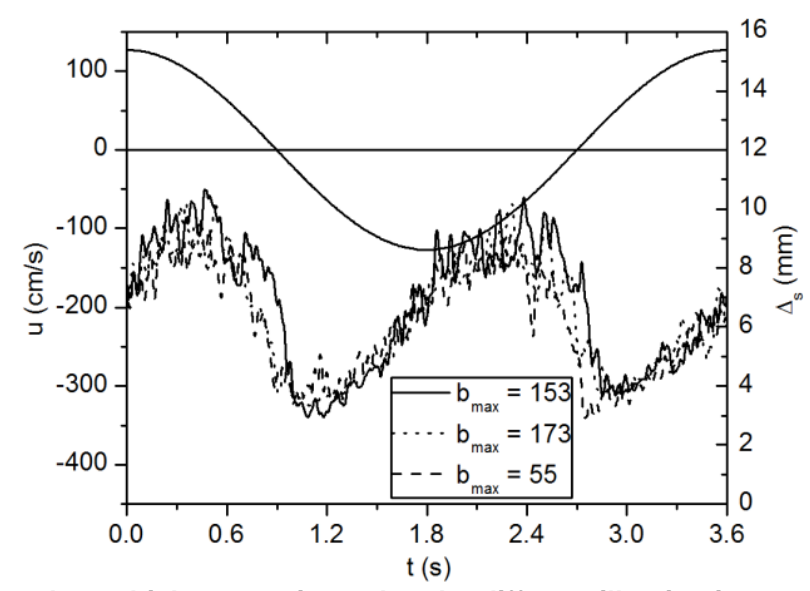

Figure 4. Temporal sheetflow layer thickness estimated under different illumination conditions for case 18 


\section{MEASURED SHEETFLOW LAYER THICKNESS}

Figures 5 to 7 show some examples of instantaneous sheetflow layer thickness that is measured in the present study. Here we considered the top of sheetflow layer thickness which is visually determined by investigating several peaks of instantaneous sheetflow layer thickness. In some cases, for example in figure $6 \mathrm{a}$, it is observed that there is a maximum sheetflow layer thickness corresponding to a short duration peak occuring at around flow reversal. We assumed that it was caused by rather high turbulence due to flow deceleration and may not reflect the effect of flow intensity. These peaks therefore were removed. Figure 5 shows the influence of wave nonlinearity to sheetflow layer thickness for experimental case 13 and case 05 of which their maximum velocities are similar but wave nonlinearities are different $\left(R_{v}=0.5\right.$ for case 05 and $R_{v}=0.6$ for case 13 , respectively). It seems that the maximum sheetflow layer thickness increases with increasing asymmetric velocity index $R_{v}$. It is because for the higher wave nonlinearity, during the crest period, a larger amount of sand are entrained and remained above the sheetflow layer due to higher onshore velocity. Such amount of sand can contribute to an increase of sheetflow layer thickness when the offshore velocity occurs. Therefore it could be said that the sheetflow layer thickness is proportional with wave nonlinearity index $R_{v}$.

Figure 6 illustrates the influence of steady current to the development of sheetflow layer thickness. It is found that presence of strong steady current which is results in larger ratio $u_{c} / u_{w}$ also increase the sheetflow layer thickness. For example, the sheetflow layer thickness for experimental case 04 is about $50 \%$ higher than that of case 01 . The maximum sheetflow layer thickness is frequently related to the flow intensity (through Shield parameter) (Wilson 1989, Dohmen-Janssen 1999). It is noted that the difference of flow intensity $\left(\sim u^{2}\right)$ in these two cases is about $30 \%$ and it cannot accurately reflect the change of sheetflow layer thickness. However, this phenomenon can be explained by the concept of "pick up time" (Dohmen-Janssen 1999) which comes from the fact that flow requires sometime to erode the bed and entrain the sediment to the maximum possible level. For the same flow condition, if $T_{c}$ or $T_{t}$ is shorter compared to such "pick up time", the sediment load entrained to flow is limited by the available time to erode the sand bed. The appearance of currents in opposite direction with waves could enlarge $T_{t}$ and hence enlarge the pick-up time for sheetflow layer thickness completely developed. In order to take into account the changes of times length due to appearance of steady current, a parameter $k_{T t}$ is introduced as follows:

$$
k_{T t}=\left(\frac{T_{t}}{T_{t, w}}\right)^{0.4}
$$

where $T_{t}$ is the half wave period of collinear waves and currents and $T_{t, w}$ is the half wave period for pure waves only. $k_{T t}$ increases with increasing the ratio $u_{c} / u_{w}$ and without current, it returns unity. Therefore we assumed it can represent for appearance of steady currents.

The influence of time length to the development of sheetflow layer thickness can be more clearly seen in figure 7 where it demonstrates the instantaneous sheetflow layer thickness for different acceleration asymmetric waves. The flow loads in these two experiments are the same but sheetflow layer thickness is observed larger for the case with smaller $\beta_{t}$ (higher forward leaning degree). This is because for smaller $\beta_{t}$, the acceleration time length $T_{p t}$ (see Fig.2) is also longer and flow load has more time to develop the thickness of sheetflow layer. This is identical with what observed by Watanabe and Sato (2004) as the sheetflow layer thickness increases with increasing $\beta_{c}$ (or decreasing $\beta_{t}$ ). The sheetflow layer thickness hence is expected that it is inversely proportional with $\beta_{t}$. 

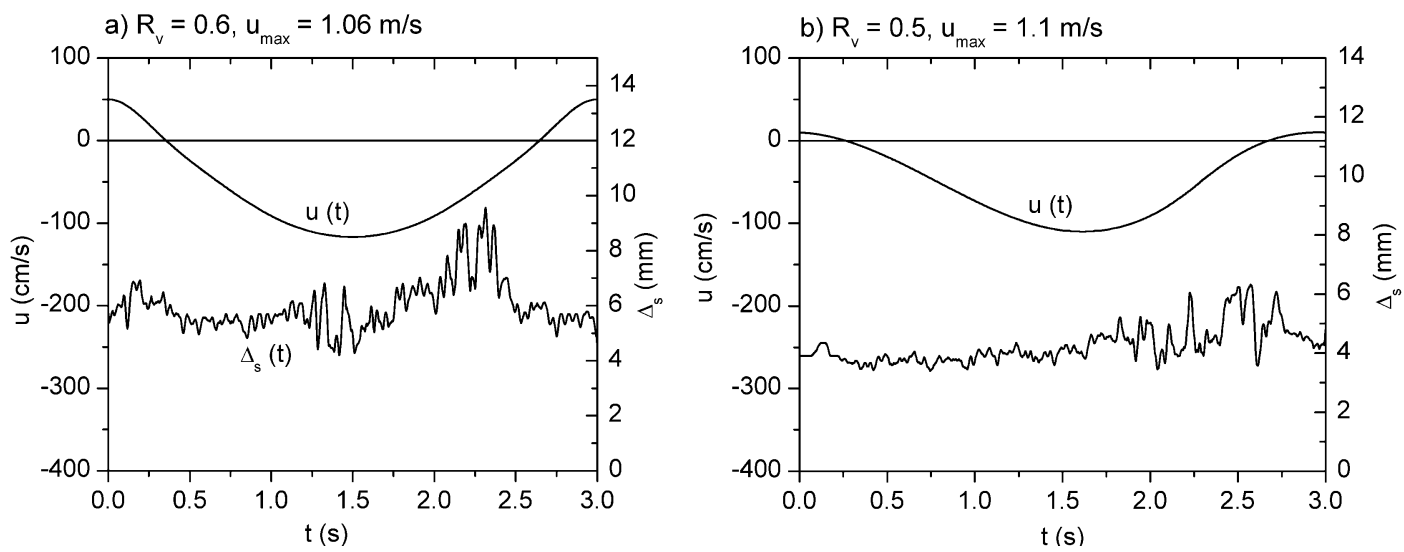

Figure 5. Instantaneous sheetflow layer thickness and particle for: a) case 13 and b) case 05

a) $\beta_{c}=0.55 ; u_{w}=1 \mathrm{~m} / \mathrm{s} ; u_{c}=0.3 \mathrm{~m} / \mathrm{s}$

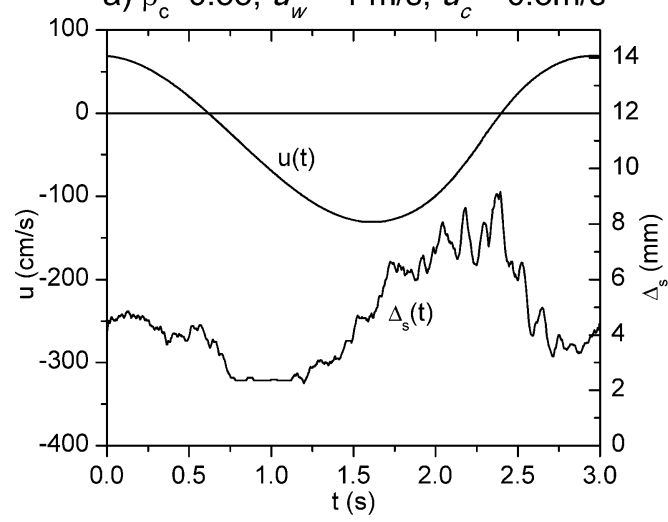

b) $\beta_{c}=0.55 ; u_{w}=1 \mathrm{~m} / \mathrm{s} ; u_{c}=0.5 \mathrm{~m} / \mathrm{s}$

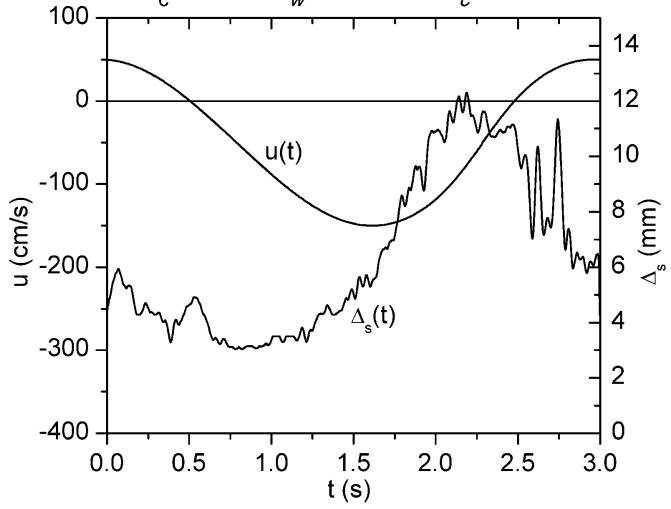

Figure 6. Instantaneous sheetflow layer thickness and particle for: a) case 01 and b) case 04

a) $\beta_{c}=0.55 ; u_{w}=1 \mathrm{~m} / \mathrm{s} ; u_{c}=0.5 \mathrm{~m} / \mathrm{s}$

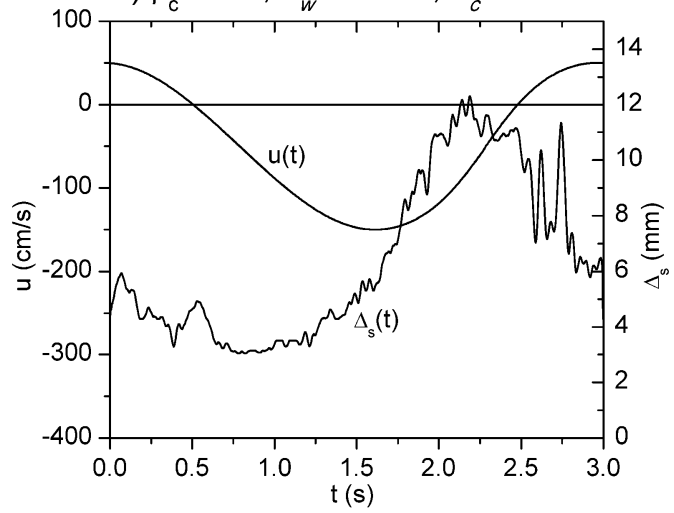

b) $\beta_{c}=0.68 ; u_{w}=1 \mathrm{~m} / \mathrm{s} ; u_{c}=0.5 \mathrm{~m} / \mathrm{s}$

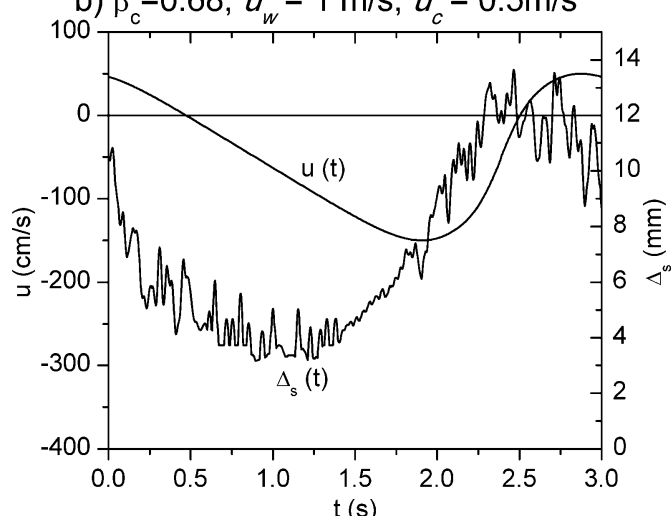

Figure 7. Instantaneous sheetflow layer thickness and particle for: a) case 04 and b) case 07

Figure 8 shows a new relationship of maximum sheetflow layer thickness as a linear function of maximum Shield parameter $\Psi_{\max }$, waves shapes indices $\beta_{t}, R_{v}$ as well as $k_{T t}$. A fairly good agreement with the experiments shows that the maximum sheetflow layer thickness can be expressed as follows:

$$
\frac{\Delta_{s}}{d_{50}}=24 R_{v} k_{T t} \frac{\Psi_{\max }}{\sqrt{2 \beta_{t}}}
$$

where $k_{T t}$ is computed by Eq.(4); $\Psi_{\max }$ is the maximum Shields parameter computed with maximum velocity $u_{\max }=u_{w, \min }+u_{c}$; the friction factor $f_{w}$ is calculated by method of Swart (1974) using $u_{t}$ as the velocity amplitude and $T=2 T_{t}$ as the oscillatory period. In sheetflow condition, the roughness height is 
often assumed as of the order of the sheetflow layer thickness (e.g, Wilson 1989, Nielsen 1992, Van Rijn 1993, Ribberink 1998). This might be caused by the intensive energy dissipation in the sheetflow layer, due to the grain-grain and grain-fluid interactions. Here, we considered the roughness height $k_{s}$ defined by Wilson (1989):

$$
k_{s}=5 \Psi_{s} d_{50}
$$

where $\Psi_{\mathrm{s}}$ is the Shields parameter estimated with $k_{s}=d_{50}$ and the equivalent sinusoidal velocity amplitude $u_{t}$ (Wilson et al. 1995). Note that Eq.(5) is derived for the case that currents are superimposed in opposite direction with waves. For the conditions when current is in direction with waves, we can apply the Eq.(5) but the subscript $t$ (trough) should be changed to $c$ (crest).

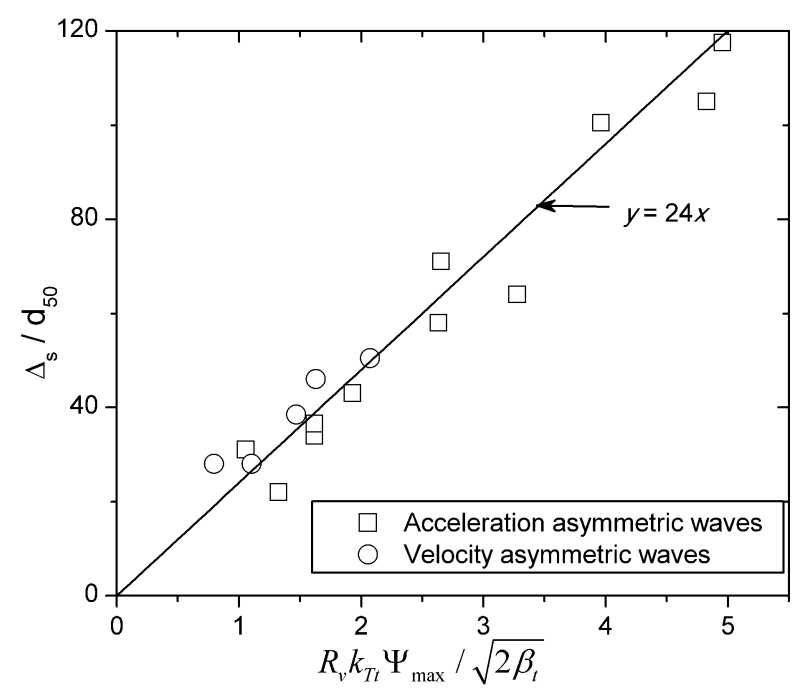

Figure 8. Measured non-dimensional sheetflow layer thickness and prediction by equation (5)

\section{NET SAND TRANSPORT FORMULA OF WATANABE AND SATO (2004)}

In 1992, Dibajina and Watanabe (DW) proposed a conceptual model based on the assumption that the net transport rates should take into account the exchange process of suspension height during one half cycle to the next half cycle. If the sand entrained and suspended by the positive (negative) velocity reach high beyond a critical height, a part of it still remained in suspension when flow reverses and can be transported into the negative (positive) direction. Since then, several subsequence models relied on DW's conception have been proposed of which Watanabe and Sato (2004) is among the latest version. This version improved the formula of Dibajnia et.al (2001) by taking into account the influence of acceleration asymmetric waves and expressed in the form as follows:

$$
\varphi_{s}=\frac{q_{s}}{w_{0} d_{50}}=0.0019 \frac{u_{c}^{\prime} T_{c}\left(\Omega_{c}+2 \beta_{c} \Omega_{t}^{\prime}\right)-u_{t}^{\prime} T_{t}\left(\Omega_{t}+2 \beta_{t} \Omega_{c}^{\prime}\right)}{T \sqrt{s g d_{50}}}
$$

where $s$ is the immersed specific gravity of sediment; $d_{50}$ is the sediment grain size; other parameters are determined by Eqs.(8) to (12).

$$
\begin{gathered}
u_{i}=\sqrt{2}\left(u_{r m s}\right)_{i} ; u_{i}^{\prime}=u_{i} / \sqrt{2\left(1-\beta_{i}\right)} \\
\Omega_{i}=q_{i}^{\prime} \min \left(1, \omega_{c r} / \omega_{i}^{\prime}\right) ; \Omega_{i}^{\prime}=q_{i}^{\prime} \max \left(0,1-\omega_{c r} / \omega_{i}^{\prime}\right) \\
q_{i}=\omega_{i} T_{i} \sqrt{s g / d_{50}} ; q_{i}^{\prime}=q_{i} /\left[2\left(1-\beta_{i}\right)\right] \\
\omega_{i}=\left(\theta_{i}-\theta_{c r}\right) d_{50} /\left(w_{0} T_{j}\right) ; \omega_{i}^{\prime}=\left(\theta_{i}^{\prime}-\theta_{c r}\right) / 2 \beta_{i}
\end{gathered}
$$




$$
\theta_{i}=u_{i}^{2} /\left(2 s g d_{50}\right)=\Psi_{i} / f_{w}
$$

Here $u_{i}, q_{i}, \omega_{i}, \theta_{i}$ are the equivalent velocity amplitude, representative suspension intensity, relative suspension height and mobility number, respectively. Other parameters with prime marks (') are modified to take into account the influence of acceleration asymmetric waves. $\Psi_{i}$ is the Shield parameter, $f_{w}$ is the friction factor, $\theta_{c r}$ is the critical mobility number for the onset of general movement $\left(\theta_{c r}=\Psi_{c r} / f_{w} \approx 5 ; \Psi_{c r}=0.05\right)$.

The sediment exchange between both half-cycles is controlled by the parameter $\omega_{i}^{\prime}$, once its critical value, $\omega_{c r}=1.2$ is exceeded. Thus, the net transport rate for each half-cycle is influenced by amount of sand that is entrained (through $q_{i}^{\prime}$ ) and amount of sand that is exchanged to next half-cycle (through $\left.\omega_{i}^{\prime}\right)$.

Fig. 9 shows the comparison of net transport rate estimated by WS04 model and with measured data for the cases with weak current $\left(u_{c} / u_{w} \leq 0.3\right)$ and for the cases with strong currents $\left(u_{c} / u_{w} \geq 0.3\right)$. The comparison comprises 260 up to date oscillatory flow measurement found in literature together with experiments in present study. To evaluate the model, we relied on the root mean square error (RMSE) between prediction and measurement (Ahmed and Sato 2003):

$$
\mathrm{RMSE}=\frac{\sqrt{\frac{1}{N} \sum_{n=1}^{N}\left|q_{\text {comp }}-q_{\text {meas }}\right|^{2}}}{\sqrt{\frac{1}{N} \sum_{n=1}^{N} q_{\text {meas }}^{2}}}
$$

where $q_{\text {comp(meas) }}$ is computed (measured) net transport rates; $N$ is the number of experiments.

Computational results reveal that the accuracy of WS04 is quite good if waves are dominants (RMSE $=0.53)$. However, considering the experiments performed with strong currents in this study, it failed to predict not only the magnitude but also the direction of net transport rate (even if magnitude problem seems to be more significant). Hence more detailed study have been made as follows in order to figure out reason of WS04's failure as well as to derive a new formula by modifying this formula set

a) $u_{c} / u_{w}<0.3$

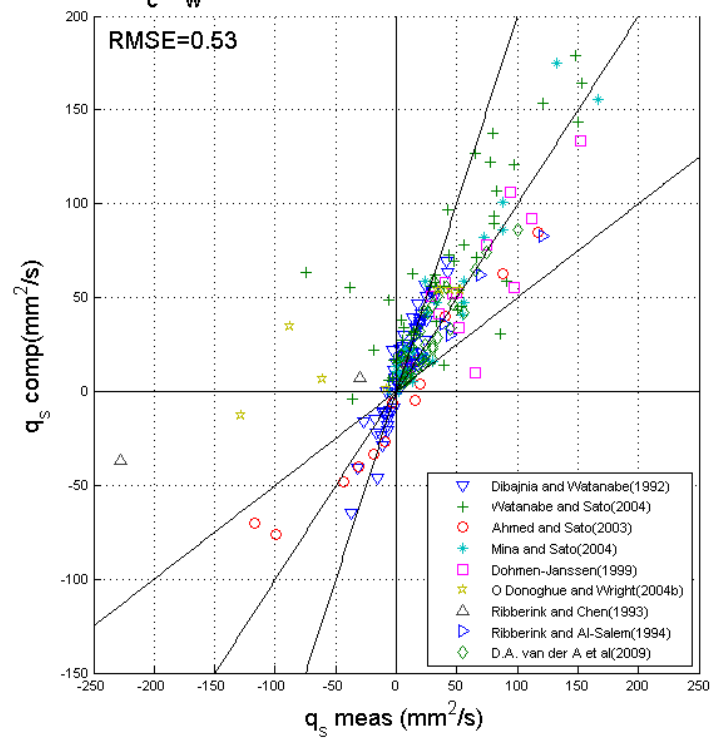

b) $u_{c} / u_{w}>0.3$

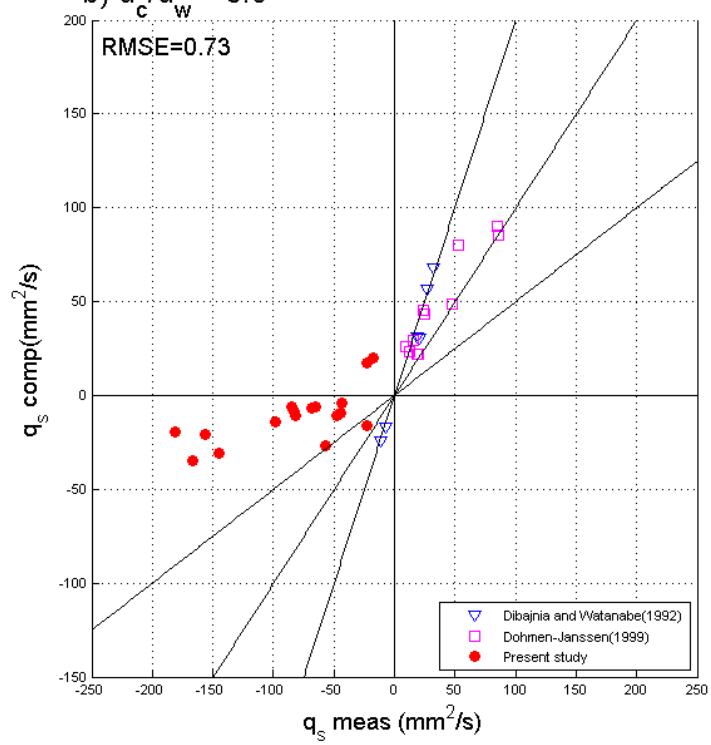

Figure 9. Measured and predicted transport rates by WS04 model for: a) cases with weak current and b) cases with strong currents. Three oblique lines demonstrate: the perfect agreement between prediction and measurement (center line), and where prediction equal to $50 \%$ and $\mathbf{2 0 0} \%$ of experimental measurement (two other lines), respectively 


\section{A NEW SAND TRANSPORT RATE FORMULA FOR WAVES AND CURRENTS}

\section{Suspension height and settling velocity in Dibajnia and Watanabe conception}

Figure 10 shows the variation with $u_{w, \max }$ of the four net transport rate components $\phi_{c}, \phi_{t}, \phi_{c}^{\prime}, \phi_{t}^{\prime}$ computed from $\Omega_{c}, \Omega_{t}, \Omega^{\prime}$, and $\Omega^{\prime}{ }_{t}$ using WS04 model for experimental conditions: $u_{c}=-0.5 \mathrm{~m} / \mathrm{s}, \beta_{c}=$ $0.55, R_{v}=0.5$ :

$$
\begin{gathered}
\phi_{c(t)}=0.0019 \frac{u_{c(t)}^{\prime} T_{c(t)} \Omega_{c(t)}}{T \sqrt{s g d_{50}}} \\
\phi_{c(t)}^{\prime}=0.0019 \frac{2 \beta_{t(c)} u_{t(c)}^{\prime} T_{t(c)} \Omega^{\prime}}{T \sqrt{s g d_{50}}}
\end{gathered}
$$

It is clearly seen that sediment is carried to offshore direction mainly by contribution of $\phi_{t}$ (for $\left.u_{w, \max }<1.5 \mathrm{~m} / \mathrm{s}, \phi_{c}^{\prime}=0\right)$. Meanwhile, $\phi_{c}$ and $\phi_{t}^{\prime}$ represent for portions of sand deposited in onshore direction but $\phi_{t}^{\prime}$ is of two to three times larger than $\phi_{c}$ (Fig.10). The reason is that flow load in crest cycle is smaller than that in trough cycle due to appearance of the strong opposite current. Hence, the amount of sand entrained to suspension under the action of positive velocity, $q_{c}{ }_{c}$, is also much smaller than the component, $q^{\prime}{ }_{t}$. Therefore, if neglecting $\phi_{c}$ component, it seems that the failure of WS04 model mainly comes from an underestimation of the sum $\left(\phi_{t}-\phi_{t}^{\prime}\right)$ or $\phi_{t} / \phi_{t}^{\prime}$. Referring to the definition of $\phi_{t}$ and $\phi_{t}{ }^{\prime}$, we may express as:

$$
\begin{gathered}
\phi_{t} \propto \frac{u_{t}^{\prime} T_{t} q_{t}^{\prime}}{T \sqrt{s g d_{50}}}\left(\frac{\omega_{c r}}{\omega_{t}^{\prime}}\right) \\
\phi_{t}^{\prime} \propto \frac{u_{c}^{\prime} T_{c} q_{t}^{\prime}}{T \sqrt{s g d_{50}}}\left(1-\frac{\omega_{c r}}{\omega_{t}^{\prime}}\right)
\end{gathered}
$$

For a designed wave combined current profile, the ratio $u_{t}^{\prime} T_{t} / u_{c}^{\prime} T_{c}$ is known, hence it is notable that an underestimation of $\phi_{t} / \phi_{t}^{\prime}$ is resulted from an overestimation of $\omega_{t}^{\prime}$ or that of representative suspension height, $\Delta_{t}^{\prime}$ in DW type model because of:

$$
\begin{gathered}
\frac{\phi_{t}}{\phi_{t}^{\prime}} \propto \frac{1}{\omega^{\prime}{ }_{t} / \omega_{c r}-1} \propto \frac{\omega_{c r}}{\omega^{\prime}{ }_{t}} \propto \frac{1}{\omega^{\prime}{ }_{t}} \\
\omega_{i}^{\prime} \propto \frac{\Delta_{i}^{\prime}}{w_{0} T_{i}} \\
\Delta_{i}^{\prime}=\frac{u_{i}^{2}}{2 s g \sqrt{2 \beta_{i}}}
\end{gathered}
$$

Representative suspension height $\Delta_{i}^{\prime}$ is derived based on assumption that the flow kinetic energy $\left(E_{k}=\rho V u_{\mathrm{i}}^{2} / 2\right)$ is completely transferred to the required potential energy $\left(E_{p}=\left(\rho_{s}-\rho\right) V \Delta_{i}\right)$ to raise up the sand particles through the strong but confined eddies existing inside the water body. Derivation of DW concept for $\Delta_{i}^{\prime}$ can be understood as it represents for the height at gravity centre of suspended sand along vertical position. Such gravity centre of suspended sand particle should be correlated with the sheetflow layer thickness. This is sound in the sense that almost sands are contained and transported within the sheetflow layer (Dohmen-Janssen, 1999). However, as shown in figure 11, sheetflow layer thickness measured in present study is about 4-6 times larger than predicted by Eq.(20). This is because sheetflow layer thickness could be limited by the turbulent kinetic energy dissipation due to high sand concentration inside sheetflow layer (Da Silva et al. 2006). So far, it is somehow difficult to quantitatively estimate the turbulent part. Therefore, it is expected that a more appropriate description 
for representative suspension height which is matched with observation could help improve the performance of WS04 model.

Another parameter that controls $\omega_{i}^{\prime}$ is the settling velocity which is assumed equal to free settling velocity at clear water. In sheetflow condition, this seems unacceptable since such settling velocity gradually decreases due to high sand concentration inside the sheetflow layer. Under such circumstances, the hindered settling velocity in high sand concentrations proposed by Richardson and Zaki (1954) is widely accepted:

$$
w_{h s}=\left(1-C_{v}\right)^{n} w_{0}
$$

Here, $w_{h s}$ is the settling velocity due to hindered settling and $C_{v}$ is the volumetric sediment concentration. $w_{0}$ is the free settling velocity of sediment particle at still water. The exponent $n=2.3$ 4.6 depends on sand Reynolds number (Fredsøe and Deigaard 1992, p200). For very fine to medium sands, van Rijn (1984) suggested a value $n=4$.

Throughout the sheetflow structure, measurements from Dohmen-Janssen (1999) and O'Donoghue and Wright (2004a) show that there is a location where sand concentration is more or less constant through wave cycles. This elevation is described as the top of pick-up layer which corresponds to the boundary between the pick-up layer where the concentrations is in anti-phase with the main flow and the upper sheetflow layer where the concentrations tends to be in phase with the main flow. Experiments with different sand sizes reveal that the concentration value at that position lies around $600 \mathrm{~g} / \mathrm{l}$. In addition, sand concentrations in sheetflow are approximately the same for different sands and only the thickness of sheetflow layer varies (Dohmen-Janssen et al. 2001). Meanwhile, the top of pickup layer at which concentration is more or less constant can be seen as a fixed point about which sand concentration profile pivot during the flow cycles (O'Donoghue and Wright 2004a). This means the centre of sheetflow layer thickness might be located around this point. Therefore, it is simply considered that the sand settling velocity at this elevation can be represented for the mean settling velocity inside the sheetflow layer. Using Eq.(21) with $n=4$, for the fine and medium sand size, if the suspended sediment concentration reaches $600 \mathrm{~g} / \mathrm{l}$, the hindered settling velocity could reduce to $36 \%$ of settling velocity of sand particle at clear water. The mean settling velocity inside the sheetflow layer then can be expressed as:

$$
\bar{w}_{h s}=0.36 w_{0}
$$

The aim to briefly determine hindered settling velocity is that it may help to figure out the critical value of $\omega_{c r}$ which will be described in detail in next section.

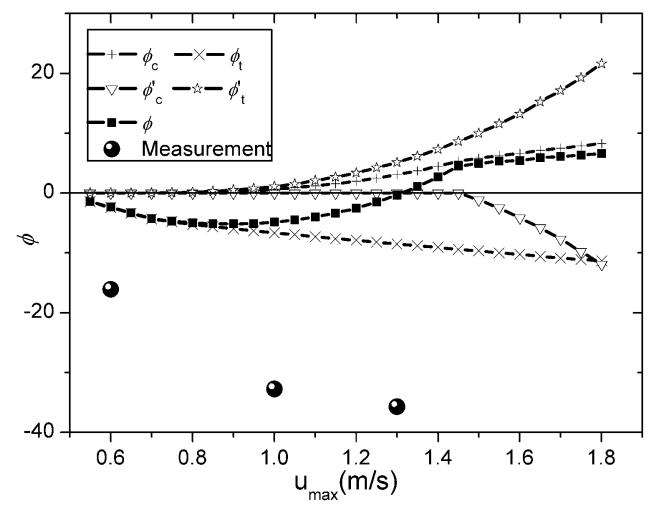

Figure 10. Contribution of net transport components computed by WS04 model and measured data for experimental condition: $u_{c}=-0.5 \mathrm{~m} / \mathrm{s}, \beta_{c}=0.55$ 


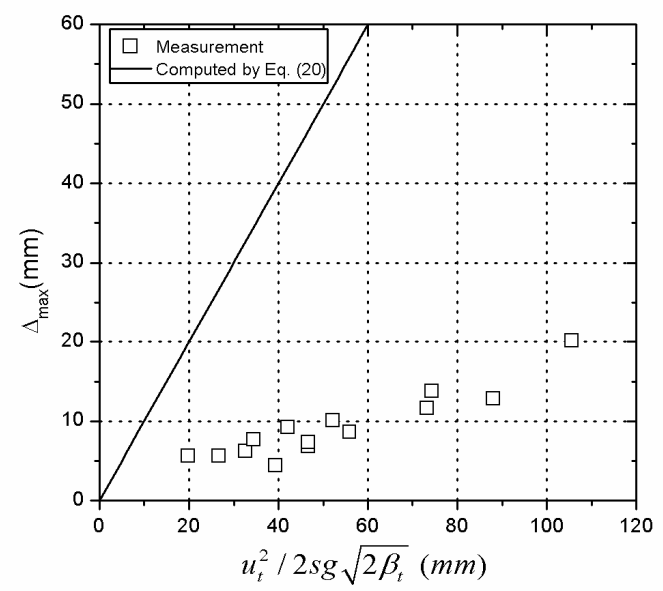

Figure 11. Measured non-dimensional sheetflow layer thickness and prediction by Eq.(20)

\section{New net transport rate formula}

The expression of sheetflow layer thickness was introduced in a new net sediment transport formulae which is rearranged to appear in similar form with WS04 model as follows:

$$
\begin{gathered}
\varphi_{s}=\frac{q_{s}}{w_{0} d_{50}}=0.3 \frac{u_{c}^{\prime} T_{c}\left(\Omega_{c}+2 \beta_{c} \Omega_{t}^{\prime}\right)-u_{t}^{\prime} T_{t}\left(\Omega_{t}+2 \beta_{t} \Omega_{c}^{\prime}\right)}{T \sqrt{s g d_{50}}} \\
\left\{\begin{array}{l}
\omega^{\prime}{ }_{i} \leq \omega_{c r}\left\{\begin{array}{l}
\Omega_{i}=q^{\prime}{ }_{i} \\
\Omega_{i}^{\prime}=0
\end{array}\right. \\
\omega_{i}^{\prime}>\omega_{c r}\left\{\begin{array}{l}
\Omega_{i}=q^{\prime}{ }_{i}\left(\frac{\omega_{c r}}{\omega^{\prime}{ }_{i}}+\left(1-\gamma_{i}\right)\left(1-\frac{\omega_{c r}}{\omega^{\prime}}\right)\right) \\
\Omega_{i}^{\prime}{ }_{j}=\gamma_{i} q_{i}^{\prime} \frac{\omega_{i}^{\prime}-\omega_{c r}}{\omega^{\prime}{ }_{i}}
\end{array}\right. \\
\theta_{i}=R_{v} k_{T i}\left(\Psi_{i}-\Psi_{c r}\right) ; \theta_{i}^{\prime}=\theta_{i} / \sqrt{2 \beta_{i}} \\
\omega_{i}=\frac{\theta_{i} d_{50}}{w_{0} T_{i}} ; \omega_{i}^{\prime}=\frac{\theta_{i}^{\prime} d_{50}}{2 \beta_{i} w_{0} T_{i}} \\
q_{i}=\omega_{i} T_{i} \sqrt{\frac{s g}{d_{50}}} q_{i}^{\prime}=\frac{q_{i}}{2\left(1-\beta_{i}\right)} \\
k_{T i}=\left(\frac{T_{i}}{T_{i, w}}\right)^{0.4}
\end{array}\right.
\end{gathered}
$$




$$
\left\{\begin{array} { l l } 
{ \gamma _ { c } = 1 } & { \text { if } \frac { u _ { t } } { u _ { c } } \geq 0 . 2 5 } \\
{ \gamma _ { c } = 4 \frac { u _ { c } } { u _ { t } } } & { \text { if } \frac { u _ { t } } { u _ { c } } < 0 . 2 5 }
\end{array} \& \left\{\begin{array}{ll}
\gamma_{t}=1 & \text { if } \frac{u_{c}}{u_{t}} \geq 0.25 \\
\gamma_{t}=4 \frac{u_{c}}{u_{t}} & \text { if } \frac{u_{c}}{u_{t}}<0.25
\end{array}\right.\right.
$$

Here, $\Psi_{i}$ is the Shields parameter; $f_{w}$ is the friction factor computed with velocity $u_{i}$ and oscillation period $2 T_{i}$ following the friction law developed by Swart (1974) with the relative roughness height computed by Eq.(6); $\Psi_{c r}=0.05$ is critical Shields parameter for onset of the initial movement; $k_{T i}$ is an intensive parameter which being considered that the presence of superimposed currents may enlarge or reduce pick up time; $R_{v}$ is asymmetric velocity index; $\beta_{i}$ is the velocity leaning index; $\gamma_{i}$ is proposed by Dibajnia et al. (2001) after considering whether kinetic energy of this half cycle is high enough to carry the remaining sand of previous cycle. The critical $\omega_{c r}$ is determined by considering that the exchange process will occur whenever the falling time of suspended sand within the representative suspension height or sheetflow layer thickness longer than a representative half-cycle period $2 \beta_{i} T_{i}$ :

$$
\begin{gathered}
\frac{\Delta_{i}^{\prime}}{2 \beta_{i} T_{i} \bar{w}_{h s}} \geq 1 \\
\Delta_{i}^{\prime}=24 \theta_{i}^{\prime} d_{50} \\
\frac{24 \theta_{i}^{\prime} d_{50}}{0.36 w_{0} * 2 \beta_{i} T_{i}} \geq 1 \Rightarrow 67 \omega_{i}^{\prime} \geq 1 \Rightarrow \omega_{c r} \approx 0.015
\end{gathered}
$$

\section{Comparison between measurements and computations}

Figure 12 shows the net transport rates computed by present formula with 260 experimental data being taken into account. The overall score for predictions with strong current cases (Fig.12b) is apparently much better. However, for that of weak current cases (Fig.12a), it is attributed that the new model does not show the well performance in comparison with WS04 model. Table 2 compares the root mean square error between non-dimensional net transport rates calculated by current formula and WS04 model. Nevertheless, the evaluation is further divided into fine sand $\left(d_{50}<0.2 \mathrm{~mm}\right)$ and coarser sand $\left(d_{50} \geq 0.2 \mathrm{~mm}\right)$. The results precisely display that in circumstance of coarse sand $\left(d_{50} \geq 0.2 \mathrm{~mm}\right)$, new model not only helps improve the accuracy for predicting net transport rates under second order Stokes - cnoidal waves combined with weak currents, but also significantly enhances the prediction capacity for collinear waves and strong currents cases. The large errors merely occur for finer sand $\left(d_{50}<\right.$ $0.2 \mathrm{~mm}$ ). Dohmen-Janssen et al. (2002) and O'Donoghue and Wright (2004b) have found that under the same flow conditions, sheetflow layer thickness for very fine sand $\left(d_{50}=0.13-0.15 \mathrm{~mm}\right)$ approximately doubled that of coarser sand $\left(d_{50} \geq 0.2 \mathrm{~mm}\right)$. There is no available appropriate explanation and it might indicate the different transport for very fine sand, i.e., plug flow may easily occur with fine sand (Sleath 1999). This is not accounted in the new model and therefore may lead to its larger error. In order to take into consideration such unknown behavior for fine sand, it is assumed that the sheetflow layer thickness for fine sand cases $\left(d_{50} \leq 0.15 \mathrm{~mm}\right)$ is two times larger than that of for coarser sand as observed by prior researches. It is though that $\Delta_{i}^{\prime}$ is in linear relationship with $\theta_{i}{ }_{i}$ (shown in Eq.31), modification is made for mobility number $\theta_{i},\left(\theta_{i}^{\prime}\right)$ in Eq.(25) as follows:

$$
\theta_{i}\left(\theta_{i}^{\prime}\right)_{\left(d_{50} \leq 0.15 \mathrm{~mm}\right)}=2 \theta_{i}\left(\theta_{i}^{\prime}\right)_{\left(d_{50} \geq 0.2 \mathrm{~mm}\right)}
$$

For sand size: $0.15<d_{50}<0.2 \mathrm{~mm}, \theta_{i},\left(\theta_{i}^{\prime}\right)$ can be estimated by interpolating between mobility numbers for $\left(d_{50} \leq 0.15 \mathrm{~mm}\right)$ and that of $\left(d_{50} \geq 0.2 \mathrm{~mm}\right)$; i.e:

$$
\theta_{i}\left(\theta_{i}^{\prime}\right)=\left[1+\left(d_{50}-0.15\right) /(0.2-0.15)\right] \theta_{i}\left(\theta_{i}^{\prime}\right)_{\left(d_{50} \geq 0.2 m m\right)}
$$

Figure 13 demonstrates the net transport rates estimated by modified formula. Undoubtedly the overall score for fine sand under weak currents cases is drastically improved although a larger error is obviously seen for a small number of experiments $(N=6)$ under strong current cases. Until now, the 
reason has not clearly found yet due to scarce experiment. Hence, further research is highly required and added experiments should be conducted so as to examine the sand transport behavior for very fine sand.

\begin{tabular}{|l|l|l|l|l|}
\hline \multicolumn{7}{|c|}{ Table 2. The prediction error (RMSE) of models } \\
\hline \multirow{4}{*}{} & \multicolumn{2}{|c|}{$u_{\delta} u_{w}<0.3$} & \multicolumn{2}{c|}{$u_{\delta} u_{w} \geq 0.3$} \\
\cline { 2 - 5 } & fine & coarse & fine & coarse \\
\cline { 2 - 5 } & $N=35$ & $N=191$ & $N=6$ & $N=28$ \\
\hline WS04 & 0.760 & 0.460 & 0.173 & 0.743 \\
New model & 1.073 & 0.389 & 0.213 & 0.304 \\
New model with modified $\theta_{i}\left(\theta_{i}^{\prime}\right)$ & 0.621 & 0.389 & 0.720 & 0.304 \\
\hline
\end{tabular}

a) $u_{C} / u_{w}<0.3$

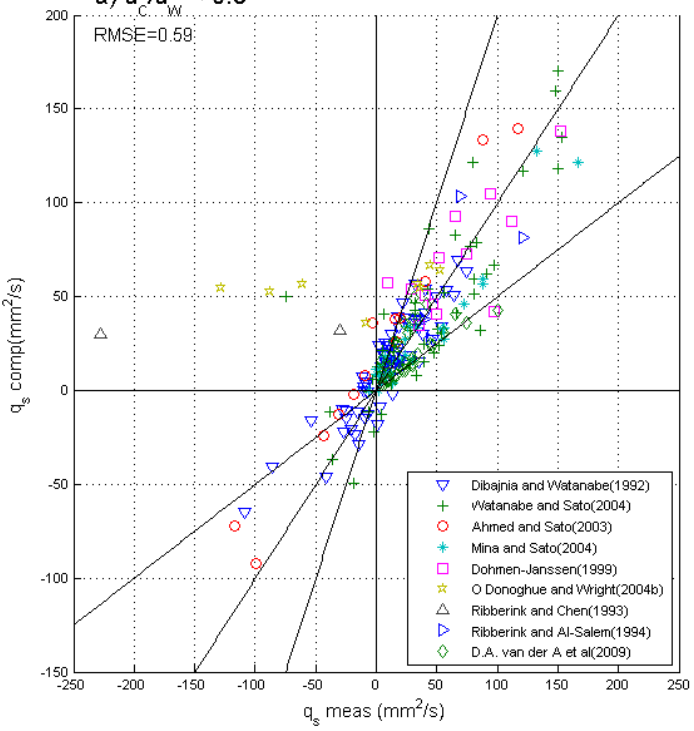

b) $u_{C} / u_{w}>0.3$

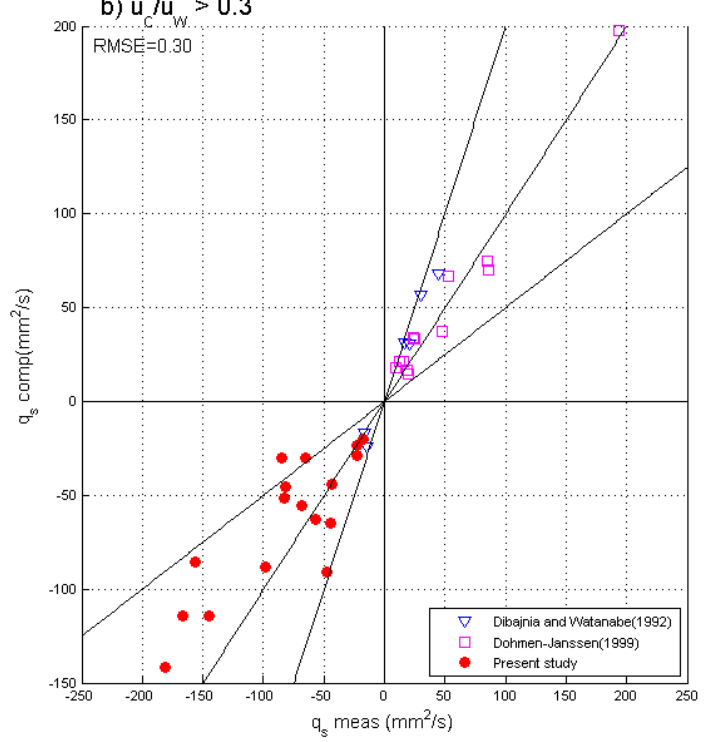

Figure 12.Comparison between computations by new formula and 260 up to date experimental cases

a) $u_{c} / u_{w}<0.3$

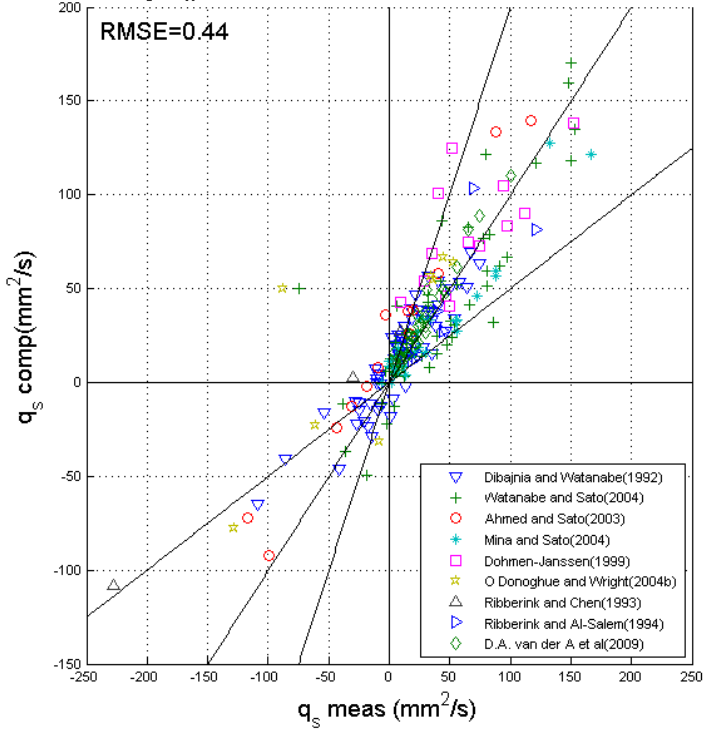

b) $u_{c} / u_{w}>0.3$

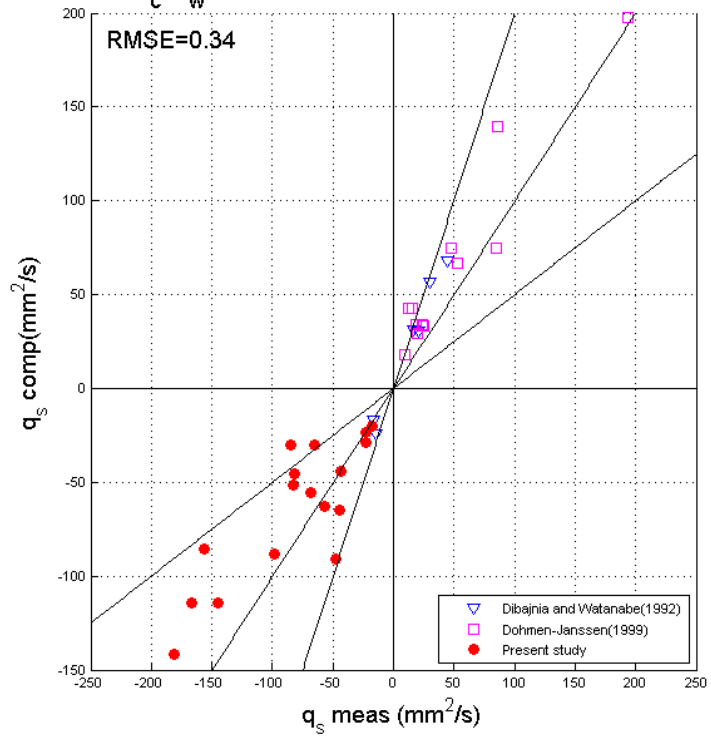

Figure 13.Comparison between computations by new formula with modified $\theta_{i}\left(\theta_{i}^{\prime}\right)$ and 260 up to date experimental cases 


\section{CONCLUSIONS}

Comprehensive experiments were conducted to investigate the behavior of sheetflow sediment transport under asymmetric waves with strong opposite currents, which have not been explored by any prior researches. Major aspects of sediment transport under asymmetric waves and currents have been studied through introducing a new technique to measure the sheetflow layer thickness on basis of image analysis. Net transport rates measurement in present study revealed that Watanabe and Sato(2004)'s formula fails to deliver an accurate prediction. The reason pointed out due to the overestimation of representative suspension height in their formula. Maximum sheetflow layer thicknesses are formulated and incorporated in a new enhanced DW type net transport rate model. The new model has been examined with high caution. In addition, its validity is verified over a wide range of experimental data.

\section{REFERENCES}

Ahmed, A. S. M. \& S. Sato (2003) A Sheetflow Transport Model for Asymmetric Oscillatory Flows: Part I: Uniform Grain Size Sediments Coastal Engineering Journal (JSCE), 45, 321-337

Da Silva, P. A., A. Temperville \& F. Seabra Santos (2006) Sand transport under combined current and wave conditions: A semi-unsteady, practical model. Coastal Engineering, 53, 897-913.

Dibajnia, M., T. Moriya \& A. Watanabe (2001) A representative wave model for estimation of nearshore local transport rate. Coastal Engineering Journal (JSCE), 43, 38.

Dibajnia, M. \& A. Watanabe. 1992. Sheet flow under nonlinear waves and currents. In Proceedings 23rd International Conference on Coastal Engineering, 2015-2028. ASCE.

Dohmen-Janssen, C. M. 1999. Grain size influence on sediment transport in oscillatory sheet flow: phase lags and mobile bed effects. In 246. Delft University of Technology.

Dohmen-Janssen, C. M., W. N. Hassan \& J. S. Ribberink (2001) Mobile-bed effects in oscillatory sheet flow. J. Geophys. Res., 106.

Dohmen-Janssen, C. M., D. F. Kroekenstoel, W. N. Hassan \& J. S. Ribberink (2002) Phase lags in oscillatory sheet flow: experiments and bed load modelling. Coastal Engineering, 46, 61-87.

Elgar, S. \& R. T. Guza (1985) Observations of bispectra of shoaling surface gravity waves. Journal of Fluid Mechanics, 161, 425-448.

Fredsøe, J. \& R. Deigaard. 1992. Mechanics of Coastal Sediment Transport World Scientific, 392pp.

Horikawa, K., A. Watanabe \& S. Katori. 1982. Sediment transport under sheetflow conditions. In Proceedings 18th International Conference on Coastal Engineering, 1335-1352. ASCE.

Mina, K. M. \& S. Sato (2004) A transport model for sheetflow based on two-phase flow. Coastal Engineering Journal (JSCE), 46, 329-367.

Nielsen, P. 1992. Coastal Bottom boundary layers and sediment transport. World Scientific.

O'Donoghue, T. \& S. Wright (2004a) Concentrations in oscillatory sheet flow for well sorted and graded sands. Coastal Engineering, 50, 117-138.

O'Donoghue, T. \& S. Wright (2004b) Flow tunnel measurements of velocities and sand flux in oscillatory sheet flow for well-sorted and graded sands. Coastal Engineering, 51, 1163-1184.

Pruszak, Z., P. V. Ninh, M. Szmytkiewicz, N. M. Hung \& R. Ostrowski (2005) Hydrology and morphology of two river mouth regions(temperate Vistula Delta and subtropical Red River delta). Oceanologia, 47, 365-385.

Ribberink, J. S. (1998) Bed-load transport for steady flows and unsteady oscillatory flows. Coastal Engineering, 34, 59-82.

Ribberink, J. S. \& A. A. Al-Salem (1994) Sediment transport in oscillatory boundary layers in cases of rippled beds and sheet flow. J. Geophys. Res., 99.

Ribberink, J. S. \& Z. Chen. 1993. Sediment transport of fine sand under asymmetric oscillatory flow. Report H840, Part VII, Delft Hydraulics, The Netherlands.

Sato, S., M. B. Kabiling \& H. Suzuki (1992) Prediction of near-bottom velocity history by a nonlinear dispersive wave model. Coastal Engineering in Japan, 35, 67-82.

Sleath, J. F. A. (1999) Conditions for plug formation in oscillatory flow. Continental Shelf Research, 19, 1643-1664.

Swart, D. H. 1974. Offshore sediment transport and equilibrium beach profiles. The Netherlands, Delft Hydraulics.

Van Rijn, L. (1993) Principles of sediment transport in rivers, estuaries and coastal seas. 715.

Watanabe, A. \& S. Sato. 2004. A sheet-flow transport rate formula for asymmetric, forward-leaning waves and currents. In Proceedings 29th International Conference on Coastal Engineering, 1703-1714. ASCE. 
Wilson, K. C. (1989) Friction of wave-induced sheet flow. Coastal Engineering, 12, 371-379.

Wilson, K. C., J. S. Andersen \& J. K. Shaw (1995) Effects of wave asymmetry on sheet flow. Coastal Engineering, 25, 191-204. 